\title{
Protection against Photooxidative Injury of Tobacco Leaves by 2-Alkenal Reductase. Detoxication of Lipid Peroxide-Derived Reactive Carbonyls ${ }^{1}$
}

\author{
Jun'ichi Mano*, Enric Belles-Boix, Elena Babiychuk, Dirk Inzé, Yoshimitsu Torii, Eiji Hiraoka, \\ Koichi Takimoto, Luit Slooten, Kozi Asada, and Sergei Kushnir
}

Science Research Center (J.M.) and Faculty of Agriculture (J.M., Y.T., E.H., K.T.), Yamaguchi University, Yoshida 1677-1, Yamaguchi 753-8515, Japan; Department of Plant Systems Biology, Flanders Interuniversity Institute for Biotechnology, Ghent University, B-9052 Ghent, Belgium (E.B.-B., E.B., D.I., S.K.); Vrije

Universiteit Brussel, Laboratorium voor Biofysica, 1050 Brussels, Belgium (L.S.); and Faculty of

Life Science and Biotechnology, Fukuyama University, Fukuyama 729-0292, Japan (K.A.)

\begin{abstract}
Degradation of lipid peroxides leads to the formation of cytotoxic 2-alkenals and oxenes (collectively designated reactive carbonyls). The novel NADPH-dependent oxidoreductase 2-alkenal reductase (AER; EC 1.3.1.74) from Arabidopsis (Arabidopsis thaliana), which is encoded by the gene At5g16970, catalyzes the reduction of the $\alpha, \beta$-unsaturated bond of reactive carbonyls, and hence is presumed to function in antioxidative defense in plants. Here we show that Arabidopsis AER (At-AER) has a broad substrate spectrum to biologically relevant reactive carbonyls. Besides 2-alkenals, the enzyme recognized as substrates the lipid peroxide-derived oxenes 9-oxo-octadeca-(10E),(12Z)-dienoic acid and 13-oxo-octadeca-(9E),(11Z)-dienoic acid, as well as the potent genotoxin 4-oxo-(2E)-nonenal, altogether suggesting AER has a key role in the detoxification of reactive carbonyls. To validate this conclusion by in vivo studies, transgenic tobacco (Nicotiana tabacum) plants that had 100- to 250-fold higher AER activity levels than control plants were generated. The engineered plants exhibited significantly less damage from either (1) the exogenously administered 4-hydroxy-(2E)-nonenal, (2) treatment with methyl viologen plus light, or (3) intense light. We further show that the At-AER protein fused with the Aequorea victoria green fluorescent protein localizes in cytosol and the nucleus in Bright-Yellow 2 cells. These results indicate that reactive carbonyls mediate photooxidative injury in leaf cells, and At-AER in the cytosol protects the cells by reducing the $\alpha, \beta$-unsaturated bond of the photoproduced reactive carbonyls.
\end{abstract}

Production of reactive oxygen species (ROS) such as superoxide radical, hydrogen peroxide $\left(\mathrm{H}_{2} \mathrm{O}_{2}\right)$, hydroxyl radical, and singlet oxygen intrinsically accompanies photosynthesis, and is enhanced when the absorbed light energy exceeds the capacity of the chloroplast to utilize it for $\mathrm{CO}_{2}$ assimilation (Asada et al., 1998). Under field conditions, the intensity of incident sunlight on leaves changes rapidly and irregularly as the leaves flutter in the wind or fall under the shade of clouds. The $\mathrm{CO}_{2}$ fixation capacity in the leaves cannot follow immediately, leading to transient

\footnotetext{
${ }^{1}$ This work was supported by the Fund for Scientific Research (no. G.0047.96), by a Predoctoral Human Capital and Mobility Fellowship of the European Union (41SF6694), by a Grant-in-Aid for the Promotion of Science from the Ministry of Education, Science, Sports and Culture, Japan, and by the Yamada Science Foundation.

* Corresponding author; e-mail mano@yamaguchi-u.ac.jp; fax 81-83-933-5944.

The author responsible for distribution of materials integral to the findings presented in this article in accordance with the policy described in the Instructions for Authors (www.plantphysiol.org) is: Jun'ichi Mano (mano@yamaguchi-u.ac.jp).

Article, publication date, and citation information can be found at www.plantphysiol.org/cgi/doi/10.1104/pp.105.070391.
}

light-excess situations. Thus, leaves are potentially under the threat of photooxidative stress even in mild weather (Külheim et al., 2002). To prevent photooxidative damage, plants have evolved multiple biochemical mechanisms, e.g. the xanthophyll cycle (DemmigAdams, 1990), the water-water cycle (in which ROS are scavenged and simultaneously excitation energy is dissipated; Asada, 1999), PSI-cyclic electron flows (Munekage et al., 2004), and photorespiration (Kozaki and Takeba, 1996). Likewise, plants have developed abundant antioxidants such as ascorbate, glutathione (GSH), tocopherols, carotenoids, and flavonoids. These antioxidative defense mechanisms are indispensable for plants not only to survive in adverse environments, but also to sustain normal metabolisms under mild environmental conditions.

Exposure of plant cells to oxidative stress, such as methyl viologen (MV), $\mathrm{H}_{2} \mathrm{O}_{2}$, or menadione, induces the expression of genes with apparent antioxidative functions, such as superoxide dismutase (SOD) and catalase, as well as the expression of many genes with unknown functions (Desikan et al., 2001; Vranová et al., 2002). To uncover genes that perform antioxidant functions, we have developed an expression-screening system of a cDNA library from Arabidopsis (Arabidopsis thaliana) in the yeast Saccharomyces cerevisiae for 
conferred tolerance against the oxidative agent diamide (Kushnir et al., 1995). Using the yeast strain yap $1^{-}$, which lacks the oxidative stress-response activation factor Yap1 and hence is sensitive to the stress, we identified independent cDNA clones named P1, P2, P3, and P4 (Babiychuk et al., 1995). The P1 cDNA, corresponding to the Munich Information Center for Protein Sequences (MIPS) gene code At5g16970, encoded a novel NADPH:quinone reductase-like protein. This gene was predominantly expressed in leaves, and its expression was enhanced by treatments invoking oxidative stress, suggesting that it functions in preventing photooxidative stress (Babiychuk et al., 1995).

The recombinant P1 protein (previously designated P1- $\zeta$-crystallin after its amino acid sequence homology to mammalian $\zeta$-crystallin) expressed in Escherichia coli showed an NADPH-dependent oxidoreductase activity to reduce diamide divalently and quinones univalently to semiquinones (Mano et al., 2000). Upon further pursuit of more physiologically relevant substrates, we found that the P1 protein catalyzed the reduction of the lipid peroxide-derived, cytotoxic 2-alkenals and oxenes (hereafter collectively called reactive carbonyls; Mano et al., 2002). In a catalyzed reaction, the $\alpha, \beta$-unsaturated bond of 2-alkenals was specifically reduced but the aldehyde group was retained (Fig. 1). Based on this unique activity, the International Union of Biochemistry and Molecular Biology has recently recommended the name alkenal reductase (EC 1.3.1.74) for the enzyme. We designate the enzyme accordingly, and hereafter abbreviate it AER (alkenal reductase) instead of the name we proposed earlier, NADPH:2-alkenal $\alpha, \beta$-hydrogenase (Mano et al., 2002). Only two proteins have been reported to have AER activity, AER from Arabidopsis (At-AER) and leukotriene $B_{4}$ 12-hydroxy dehydrogenase from rat (Dick et al., 2001). The specificity of the recombinant At-AER to the electron acceptors was highest for 4-hydroxy(2E)-nonenal (HNE; Mano et al., 2002), one of the most potent toxins produced from lipid peroxides (Esterbauer et al., 1991; Uchida, 2003). The AERcatalyzed reaction would significantly lower the toxicity of reactive carbonyls because the electrophilicity of the $\alpha$-carbon, which reacts with target molecules, is

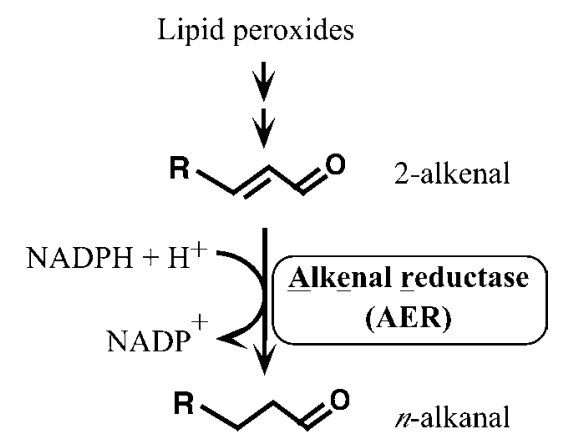

Figure 1. Selective reduction of the $\alpha, \beta$-unsaturated bond of 2-alkenal catalyzed by AER. diminished by the reduction of the unsaturated bond. These results satisfactorily explain the expected stressdefense function of At-AER.

The biochemical mechanism underlying the detoxification of reactive carbonyls has been elucidated in mammalian cells (Esterbauer et al., 1991; Uchida, 2003). There are three established routes: (1) conjugation with GSH catalyzed by the glutathione S-tranferases (GSTs); (2) oxidation of the aldehyde group to carboxylic acid by either alcohol dehydrogenase or aldehyde dehydrogenase (ALDH); and (3) reduction of the aldehyde or keto moiety to alcohol by aldo-keto reductase (AKR). In rat liver, $60 \%$ of the exogenously added HNE was metabolized by GST, alcohol dehydrogenase, and ALDH (Hartley et al., 1995). In rat heart and erythrocytes, HNE was metabolized mainly by GST and AKR (Srivastava et al., 1998, 2000). The human corneal epithelial cells that were engineered to produce higher levels of the HNE-scavenging ALDH3A1 showed higher tolerance against UV-B and UV-C (Pappa et al., 2003). For plants, in contrast, not much has been investigated. Overexpression of an alfalfa (Medicago sativa) AKR gene in tobacco (Nicotiana tabacum) improved the tolerance against drought and UV-B (Hideg et al., 2003). Arabidopsis plants that overexpressed the Arabidopsis-ALDH3 gene showed improved tolerance against drought, $\mathrm{NaCl}$, heavy metals, $\mathrm{MV}$, and $\mathrm{H}_{2} \mathrm{O}_{2}$ (Ramanjulu et al., 2003). The protection of plant cells provided by these enzymes is attributable to the detoxification of reactive carbonyls.

The catalytic efficiency of At-AER for HNE is the highest as compared with the above-mentioned enzymes, and in leaf extracts from Arabidopsis, $80 \%$ of the HNE-reducing activity was assigned to At-AER (Mano et al., 2002). The Arabidopsis genome contains 11 genes that code for the AER-homologous polypeptides, among which three were cloned as antioxidative genes (P1, P2, and P4, corresponding to the MIPS gene codes At5g16970, At5g16990, and At1g49760, respectively) in a functional screening of an Arabidopsis cDNA library for improved tolerance of the yap $1^{-}$ strain of $S$. cerevisiae against the thiol-oxidizing drug diamide (Babiychuk et al., 1995). In contrast to this abundant occurrence of AER homologs in Arabidopsis, only one or two orthologous genes are found in the whole genomes of nonplant organisms such as human, Caenorhabditis elegans, Drosophila melanogaster, S. cerevisiae, and E. coli (Nordling et al., 2002), suggesting the critical importance of the AER-family proteins in plants.

To evaluate the in planta significance of At-AER for antioxidative defense, we have generated transgenic tobacco plants that overexpress At-AER. Leaves of the At-AER-overproducing tobaccos showed higher ability to detoxify exogenously added HNE and exhibited tolerance against intense light- or MVinduced photodamage. These results indicated that the AER-catalyzed $\alpha, \beta$-hydrogenation of the reactive carbonyls contributed to the antioxidative defense in plants. 


\section{RESULTS}

\section{At-AER Has a Broad Substrate Spectrum for Lipid} Peroxide-Derived 2-Alkenals and Oxenes

The degradation of lipid peroxides in plant cells produces a variety of aldehydes and ketones. At-AER recognizes 2-alkenals with carbon chain lengths 3 to 9 (including 4-hydroxy-2-alkenals such as HNE and 4-hydroxy-(2E)-hexenal) and oxenes, which have an $\alpha, \beta$-unsaturated enone structure (Mano et al., 2002). To rationalize the in vivo function of At-AER, we further tested its substrate specificity to five derivatives of 2-alkenals or of oxenes that are relevant to oxidative stress (Table I). At-AER expressed in E. coli was purified (Mano et al., 2000) and its activity toward a possible electron acceptor was evaluated.

$(2 E),(6 Z)$-Nonadienal is produced from lipid peroxides when plant tissues are wounded (Fleming et al., 1968; Schieberle et al., 1990). This volatile dienal is a potent genotoxin that induces numerical chromosomal aberrations in mammalian cells (Dittberner et al., 1995). At-AER showed a high level of the NADPHdependent reducing activity of $(2 E),(6 Z)$-nonadienal at a similar level to that of HNE (Table I). We also tested another 2-alkenal-derivative 4-oxo-(2E)-nonenal (ONE), a potent DNA modifier produced via oxidation of HNE (Lee and Blair, 2000). Interestingly, At-AER showed a $K_{\mathrm{m}}$ value as low as $1 \mu \mathrm{M}$ and hence a high catalytic efficiency to ONE. To test biologically relevant oxenes, we chose the ketodienes 9-oxo-(10E), (12Z)-octadecadienoic acid (9-oxoODE) and 13-oxo(9E),(11Z)-octadecadienoic acid (13-oxoODE), which are the lipoxygenase products from 9- and 13-hydroperoxy-ocatadecatrienoic acids, respectively. These ketodienes accumulate in wounded and pathogeninfected leaves and cause leaf injury due to their reactivity as Michael acceptors (Vollenweider et al., 2000). As expected from its reactivity to oxenes, AtAER catalyzed the NADPH-dependent reduction of both 9- and 13-oxoODEs at substantial rates. These results show that At-AER is a universal detoxifier of

Table I. Kinetic parameters of recombinant At-AER for the lipid peroxide-derived reactive carbonyls

\begin{tabular}{|c|c|c|c|c|}
\hline Electron Acceptor & Structure & $k_{\text {cat }}$ & $K_{\mathrm{m}}$ & $k_{\mathrm{cat}} / K_{\mathrm{m}}$ \\
\hline $\mathrm{HNE}^{\mathrm{a}}$ & & $\begin{array}{r}s^{-1} \\
88.1\end{array}$ & $\begin{array}{r}\mu \mathrm{M} \\
13.4\end{array}$ & 6.5 \\
\hline$(2 E),(6 Z)$-Nonadienal & & 33.9 & 11.3 & 3.0 \\
\hline ONE & & 20.1 & 1.24 & 16 \\
\hline 9-OxoODE & & 0.94 & 10.0 & 0.09 \\
\hline 13-OxoODE & & 1.10 & 3.92 & 0.28 \\
\hline 3-Nonen-2-one & & 18.9 & 0.673 & 28 \\
\hline
\end{tabular}

${ }^{\mathrm{a} M a n o}$ et al. (2002).
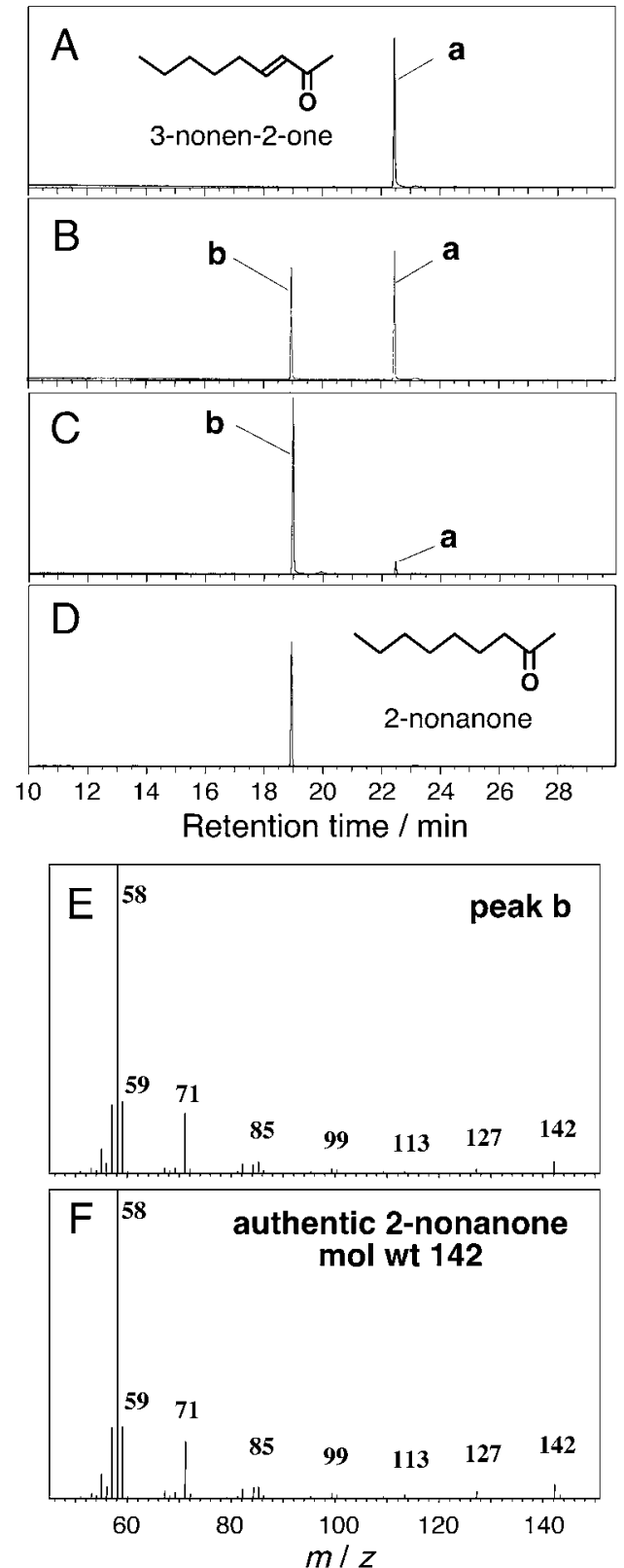

Figure 2. GC/MS evidence for the selective reduction of the $\alpha, \beta$-unsaturated bond of 3-nonen-2-one with At-AER. Reaction mixture (5 mL) contained $100 \mu \mathrm{m}$ 3-nonen-2-one, 0 to $200 \mu \mathrm{M} \mathrm{NADPH}$, and $75 \mathrm{~nm}$ At-AER in $50 \mathrm{~mm}$ MES- $\mathrm{NaOH}, \mathrm{pH}$ 6.0. After the reaction at $30^{\circ} \mathrm{C}$ for $10 \mathrm{~min}$, lipid-soluble substances were extracted from the reaction mixture with $5 \mathrm{~mL}$ of diethylether. The ether phase was dehydrated with anhydrous $\mathrm{Na}_{2} \mathrm{SO}_{4}$ and was concentrated by evaporation. A to $\mathrm{E}, \mathrm{GC}$ of the reaction products extracted from the reaction mixture with the molar ratio of NADPH:3-nonen-2-one; 0:1 (A), 0.5:1 (B), 1:1 (C), and that of authentic 2-nonanone (D). E and F, MS of peak $b$ in section $C$ and 2-nonanone, respectively.

the reactive carbonyls that are potentially generated in oxidatively stressed cells.

We have clarified that At-AER selectively catalyzes the reduction of the $\alpha, \beta$-unsaturated bond of 2-alkenals to produce $n$-alkanals (Mano et al., 2002). To examine 
whether or not the same reaction is applied to oxenes, we determined the structure of the At-AER-reduced product of an oxene, 3-nonen-2-one, to which At-AER exhibited the highest catalytic efficiency (Table I). When this oxene was reduced by NADPH with At-AER, only one product was obtained; it was identified as 2-nonanone by a gas-chromatography/ mass-spectrometry (GC/MS) analysis (Fig. 2). Even in a reaction with supraequimolar NADPH to the 3-nonen-2-one, no reduction of the ketone moiety to alcohol was observed (data not shown). Thus, AtAER specifically catalyzes the reduction of the $\alpha, \beta$ unsaturated bond and retains the carbonyl moiety in oxenes as in 2-alkenals.

\section{Characterization of Transgenic Tobacco Plants That Overexpress At-AER}

To assess the in vivo role of the At-AER, we generated transgenic tobacco plants in which the expression of At-AER was driven by the strong constitutive promoter 35S. We obtained three independent transgenic lines P1\#11, P1\#14, and P1\#18, which showed higher levels of both the mRNA and the protein of At-AER than did the control line, which had been transformed with an empty vector. No apparent difference in growth was observed among these lines when they were cultured with a day light at $100 \mu \mathrm{mol}$ $\mathrm{m}^{-2} \mathrm{~s}^{-1}$, as described in "Materials and Methods." We evaluated the levels of At-AER in the leaf extracts from the transgenic and control plants by the HNE-reducing activity and by immunoblotting. Control tobacco showed an HNE-reducing activity of $0.12 \mathrm{nmol} \mathrm{s}^{-1}$ (mg protein) $^{-1}$ (Table II), which was comparable to that in Arabidopsis leaves, $0.39 \mathrm{nmol} \mathrm{s}^{-1}(\mathrm{mg}$ protein) ${ }^{-1}$ (Mano et al., 2002). The transgenic lines P1\#11, P1\#14, and P1\#18 showed 100- to 250-fold higher activity of NADPH-dependent HNE reduction. The addition of the antiserum against recombinant AtAER (Mano et al., 2002) to the assays suppressed $98 \%$ of this activity, indicating that the enhanced activities in the transgenic lines were mostly ascribed to the overexpressed At-AER. By immunoblotting, the endogenous At-AER protein in Arabidopsis leaves was detected as a single band (Fig. 3). In contrast, no immunoreactive protein was detectable in the leaves of control tobacco although they contained a significant level of NADPH-dependent HNE-reducing activity. The activity in the control tobacco might be due to another kind of protein, such as AKR. In At-AERoverproducing lines P1\#11, P1\#14, and P1\#18, a single band of a similar molecular size was detected with the antiserum, as expected. The At-AER protein levels corresponded well with the enzyme activities in leaf extract in these transgenic tobacco lines. Thus, the functionally active At-AER protein accumulates to high levels in the transgenic plants.

To assess whether or not At-AER overexpression may have a pleiotropic effect on the activity of the antioxidant system in tobacco, we also measured the levels of the major ROS-scavenging enzymes, i.e. SOD, ascorbate peroxidase (APX), and catalase (Table II). In the At-AER-overproducing plants, these enzymatic activities were almost the same as or slightly lower than those in the control line, except that the P1\#14 line had a 1.5-fold higher SOD activity than the other lines.

\section{Elevated At-AER Protects Cells from the HNE-Induced Necrosis}

Endogenous production of HNE in plants in response to some biological stress stimuli has been reported (Kohlmann et al., 1999; Muckenschnabel et al., 2001). We verified whether or not the At-AER expressed in tobacco functions as a detoxifier against HNE in the cells. HNE was administered to detached leaves of tobacco by applying $20 \mu \mathrm{L}$ of HNE solution to a puncture site made in the leaf. In darkness, a change of leaf color from green to dark green developed concentrically from the puncture point until $48 \mathrm{~h}$ postapplication. The darkened area could be regarded as necrotic lesion because the area showed no PSII activity, as judged by the chlorophyll fluorescence parameter maximum photochemical efficiency of PSII in the dark-adapted state $\left(F_{\mathrm{v}} / F_{\mathrm{m}}\right.$; van Kooten and Snel, 1990) to be zero, and was bleached upon exposure to a weak light $\left(30 \mu \mathrm{mol} \mathrm{m}{ }^{-2} \mathrm{~s}^{-1}\right)$ for $6 \mathrm{~h}$, whereas the surrounding nonaffected area showed a full PSII activity $\left(F_{\mathrm{v}} / F_{\mathrm{m}}\right.$ value 0.8$)$ and was not bleached upon illumination. When leaves were illuminated at $30 \mu \mathrm{mol} \mathrm{m} \mathrm{m}^{-2} \mathrm{~s}^{-1}$ from the beginning of incubation, bleaching of the leaf tissue, i.e. necrosis, developed concentrically. The extent of necrosis was not affected by this intensity of light.

Table II. Activities of AER, SOD, APX, and catalase in leaves of control and At-AER-overproducing tobacco plants

The enzyme activities in total leaf protein extracts were determined as described in "Materials and Methods." The electron acceptor for AER assay was HNE at $100 \mu \mathrm{M}$. Data are represented as means \pm SD $\left(\mathrm{nmol} \mathrm{s}^{-1}[\mathrm{mg} \text { protein }]^{-1}\right.$, unless otherwise specified). Measurements were carried out on four plants per line. Asterisks indicate significant differences as compared with control $(P<0.05)$.

\begin{tabular}{|c|c|c|c|c|}
\hline Enzyme & Control & $\mathrm{P} 1 \# 11$ & P1\#14 & $\mathrm{P} 1 \# 18$ \\
\hline AER & $0.12 \pm 0.03$ & $12.0 \pm 1.6^{*}$ & $13.0 \pm 2.5^{*}$ & $30.8 \pm 7.7^{*}$ \\
\hline SOD/units (mg protein) ${ }^{-1}$ & $24.3 \pm 3.0$ & $24.4 \pm 2.2$ & $36.6 \pm 3.1^{*}$ & $25.5 \pm 5.9$ \\
\hline APX & $34.0 \pm 1.3$ & $26.7 \pm 7.8$ & $28.7 \pm 7.7$ & $37.1 \pm 7.2$ \\
\hline Catalase & $433 \pm 21$ & $358 \pm 59$ & $442 \pm 32$ & $340 \pm 6.0^{*}$ \\
\hline
\end{tabular}




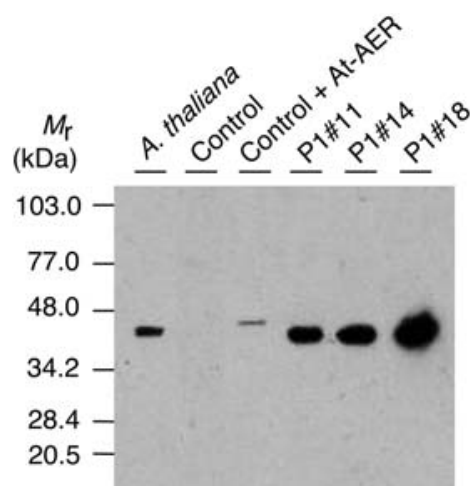

Figure 3. Accumulation of the At-AER protein in the transgenic tobaccos as revealed by immunoblotting with a rabbit antibody against the recombinant At-AER (Mano et al., 2002). Leaf extracts from tobacco or Arabidopsis corresponding to $20 \mu \mathrm{g}$ proteins were separated on SDS-PAGE, reacted with the antibody, and detected with alkaline phosphatase (Boehringer Mannheim). Control represents the empty vector-transformed tobacco. In Control + At-AER, 2 ng of recombinant At-AER was added to the extract of the control plant. The recombinant At-AER had a larger $M_{r}$ because of the poly-(His) tag.

There was a possibility that the necrosis was an indirect effect of HNE, specifically, it was caused by a metabolite of HNE. When the HNE at $10 \mathrm{~mm}$ in a $20-\mu \mathrm{L}$ solution was treated with the recombinant At-AER and $10 \mathrm{~mm}$ NADPH for $10 \mathrm{~min}$ prior to the application on the leaf, under which condition more than $95 \%$ of the HNE was reduced, it did not cause necrosis (data not shown). This excludes the abovementioned possibility and confirms that the necrosis was caused by HNE.

Necrosis areas resulted from HNE at various concentrations in the At-AER overproducing, and the control tobaccos are presented in Figure 4. HNE at higher concentrations resulted in larger necrosis areas in both the control and the At-AER overproducers, but leaves from the overproducers developed significantly smaller necrosis when $5 \mathrm{~mm}$ and $10 \mathrm{~mm}$ HNE was applied. Thus, the ectopically expressed At-AER conferred tolerance against HNE on tobacco leaves.

\section{At-AER Confers Higher Tolerance against MV-Induced Oxidative Stress}

Because overproduced At-AER in leaf cells detoxified $\mathrm{HNE}$, it was expected that the At-AER-overproducing tobacco plants would show a tolerance to oxidative stress if reactive carbonyls are produced during the stress and if the carbonyls thus produced mediate oxidative damages. To verify this hypothesis, we stressed leaves photooxidatively with MV plus light. The MV/ light treatment enhances the photoproduction of $\mathrm{O}_{2}^{-}$in chloroplasts and the derived $\mathrm{H}_{2} \mathrm{O}_{2}$ is primarily responsible for cellular injury (Mano et al., 2001). Participation of reactive carbonyls, if at all, in cellular damages would be masked by direct effects of ROS under the conditions of a large flux of $\mathrm{O}_{2}{ }^{-}$production. Indeed, as described below, we could confirm that the overexpression of At-AER protected leaf cells under certain combinations of MV concentration and light intensity, but when the leaves were treated with MV at $2 \mu \mathrm{M}$ or higher, or when the light intensity was higher than $280 \mu \mathrm{mol}$ photons $\mathrm{m}^{-2} \mathrm{~s}^{-1}$, all the tested lines suffered damages to the same extents, most probably by the direct action of ROS, and no tolerance due to the overexpressed At-AER was observed (data not shown).

The tolerance of the At-AER-overproducing tobaccos was observed under relatively mild stress conditions as follows: In the first set, leaf discs were first let absorb MV at $0.2 \mu \mathrm{M}$ or $0.4 \mu \mathrm{M}$ in darkness, illuminated at $280 \mu \mathrm{mol}$ photons $\mathrm{m}^{-2} \mathrm{~s}^{-1}$ for $2 \mathrm{~h}$, and then further incubated in darkness for $20 \mathrm{~h}$ (Fig. 5). In this mildstress treatment, the production of $\mathrm{O}_{2}{ }^{-}$is confined to chloroplasts (Slooten et al., 1995). Evaluation of the leaf cell damage was based on the ion leakage from leaf discs, as judged by the conductivity of leaf disc-floating solution, and on the PSII activity as judged by the chlorophyll fluorescence parameter $F_{\mathrm{v}} / F_{\mathrm{m}}$ (van Kooten and Snel, 1990). In the absence of MV, the ion leakage of the floating solutions of P1\#11 and P1\#14 lines was slightly higher than that of the control line. When leaf discs were treated with MV (0.2-0.4 $\mu \mathrm{M})$, the conductivity became higher for all the tested lines, reflecting cellular injury due to photooxidative stress caused by MV plus light. Obviously, P1\#14 and P1\#18 showed smaller increases in conductivity than the control did. In accordance with the conductivity change, the $F_{\mathrm{v}} / F_{\mathrm{m}}$ values became lower by the treatment with

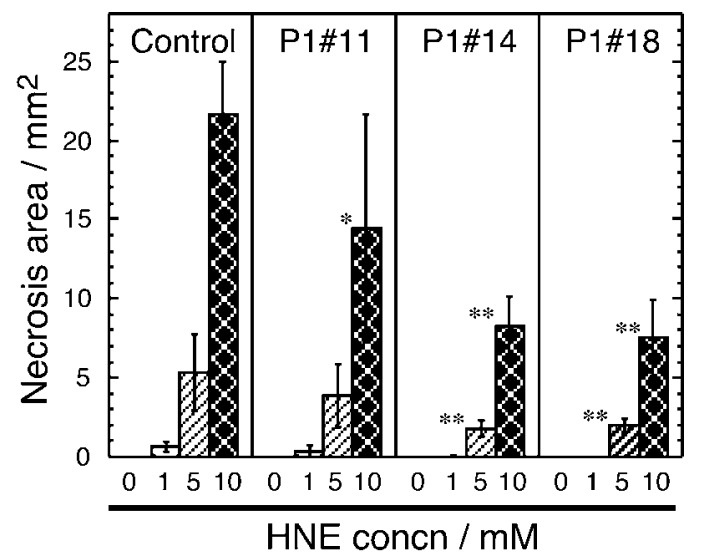

Figure 4. Alleviation of HNE-induced leaf necrosis by the overexpression of At-AER. Fully expanded, mature leaves of a similar size were collected from 11 - to 12 -week-old plants, three plants for each line. A $5-\mathrm{cm} \times 5-\mathrm{cm}$ section of a leaf was put in a petri dish. Cut edges were covered with moist cotton wool to prevent drying. In each section, 12 punctures spaced by at least $5 \mathrm{~mm}$ apart were made using a hypodermic syringe needle. To the 12 punctures in a section, three of the same HNE solution $(20 \mu \mathrm{L}$ each) $\times$ four concentrations $(0,1,5$, and $10 \mathrm{~mm}$ ) were applied. Leaf sections were kept in a moist atmosphere at $28^{\circ} \mathrm{C}$ under a $16 / 8-\mathrm{h}$ photoperiod at $30 \mu \mathrm{mol} \mathrm{m} \mathrm{m}^{-2} \mathrm{~s}^{-1}$ with whitefluorescent lamps. Two days after incubation leaf necrosis was evaluated by the bleached area, and the three values for an HNE solution at the same concentration in a leaf were averaged. Represented results are the means and SD of the averages obtained from three plants of each line. Single and double asterisks represent significant differences from the corresponding control data using a two-sided Student's $t$ test; $P<0.05$ and 0.01 , respectively. 
Figure 5. Changes of ion leakage and PSII activity in the MV/light-treated leaf disks of control, $\mathrm{P} 1 \# 11, \mathrm{P} 1 \# 14$, and $\mathrm{P} 1 \# 18$ plants. Plants were grown on soil in growth cabinets in a 16/8-h photoperiod at $280 \mu \mathrm{mol}$ photons $\mathrm{m}^{-2} \mathrm{~s}^{-1}$, with day/night temperatures of $22^{\circ} \mathrm{C} / 18^{\circ} \mathrm{C}$ to the ninth to tenth leaf stage. Leaves of similar size and age (fifth to seventh leaf position from the bottom) were used. Leaf discs were let absorb MV as in "Materials and Methods," and were then illuminated for $2 \mathrm{~h}$ at $25^{\circ} \mathrm{C}$ with white light of $280 \mu \mathrm{mol}$ $\mathrm{m}^{-2} \mathrm{~s}^{-1}$. After another $20 \mathrm{~h}$ dark incubation at $28^{\circ} \mathrm{C}$, the conductivity of the floating solution for ion leakage (top section) and $F_{\mathrm{v}} / F_{\mathrm{m}}$ for PSII activity (bottom section) were determined. Data are presented as mean of the following number of plants \pm SE: for P1\#11 and control (left column), 12 plants; for $\mathrm{P} 1 \# 14$ versus control (middle column), 34 plants; for $\mathrm{P} 1 \# 18$ versus control (right column), 18 plants (0 and $0.4 \mu \mathrm{M} \mathrm{MV}$ ) or 12 plants $(0.2 \mu \mathrm{M} \mathrm{MV})$. Three leaf discs per plant were used for each treatment. Asterisks indicate significant differences as in Figure 4.

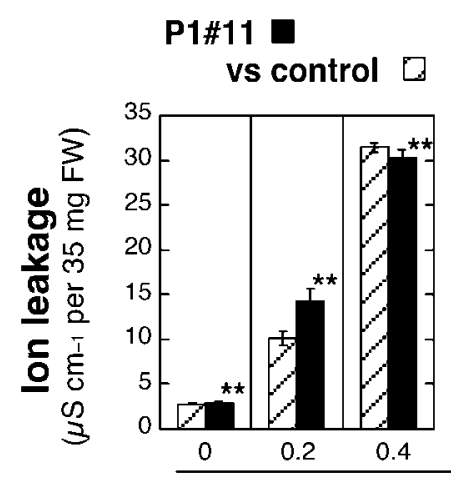

P1\#14 vs control

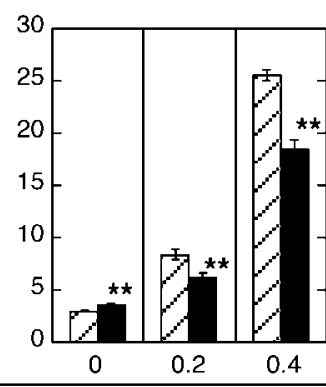

$\mathrm{MV}$ concn $/ \mu \mathrm{M}$

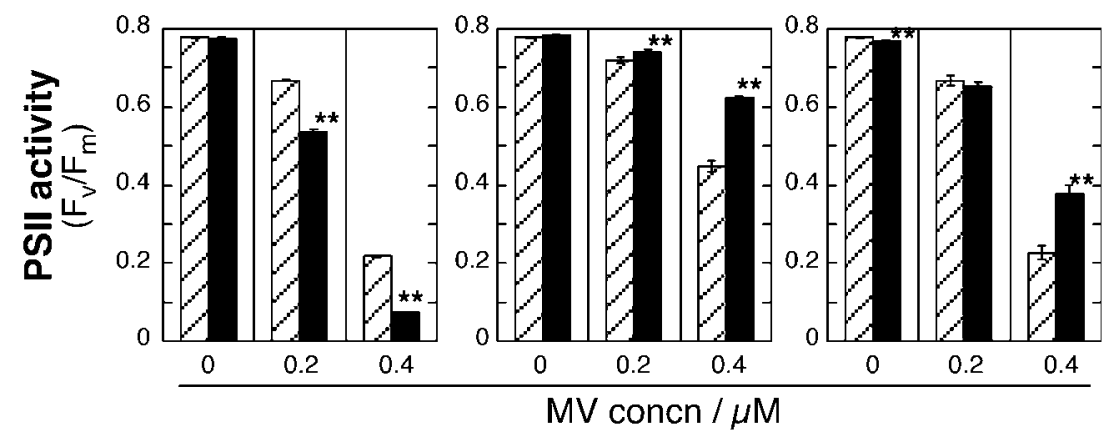

P1\#18 vs control $\square$

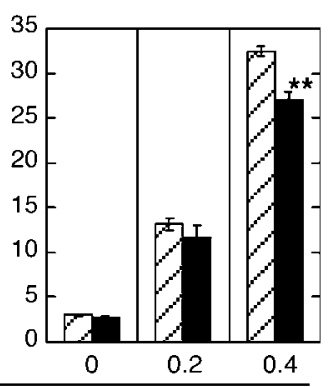

$\begin{array}{lll}0 & 0.2 & 0.4\end{array}$

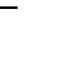



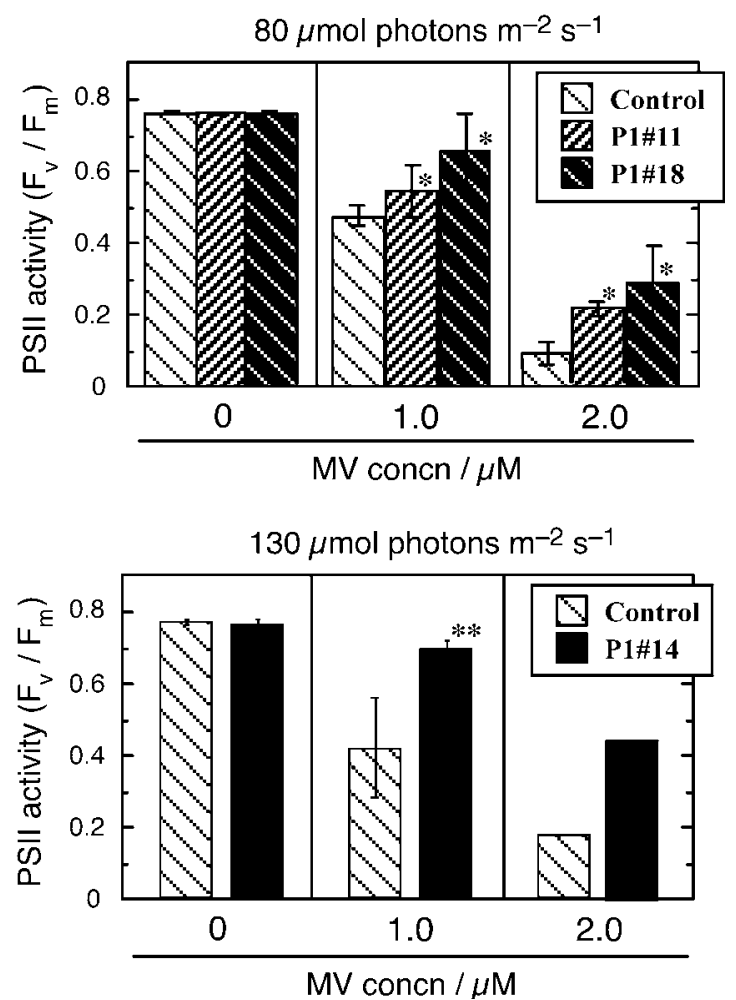

Figure 6. Tolerance in the At-AER-overproducing tobaccos against the photooxidative stress induced by the MV/light treatment, as determined by PSII activity. Leaves of similar size and age (seventh to ninth leaf from the bottom) of 12- to 13-week-old plants grown on soil were used. Fifteen leaf disks, five disks per leaf collected from three plants of each line, were treated with MV at indicated concentration and illuminated with white-fluorescent lamps at the indicated light intensity as in Figure 4. The $F_{\mathrm{v}} / F_{\mathrm{m}}$ value was determined at $20 \mathrm{~h}$ after the cessation of illumination. Top section, Comparison among the control, P1\#11, and $\mathrm{P} 1 \# 18$ lines (12 to 13 weeks old, illuminated at $80 \mu \mathrm{mol} \mathrm{m}{ }^{-2} \mathrm{~s}^{-1}$ ). Bottom section, Comparison between the control and P1\#14 lines (16 weeks old, illuminated at $130 \mu \mathrm{mol} \mathrm{m}^{-2} \mathrm{~s}^{-1}$ ). Data are presented as mean of three runs $\pm \mathrm{SD}$, except for the data of $2 \mu \mathrm{M} \mathrm{MV}$ in the bottom section (average of two runs). Asterisks indicate significant differences as in Figure 4.

that part of the activity loss could be accounted for by the local inactivation of the PSII complex, in contrast to the irreversible PSII inactivation caused by the MV/ light treatment. Notably, after the recovery the PSII activity in the At-AER-overproducing plants was still significantly higher than that in the control. Thus, the overproduced At-AER protected leaf cells from intense light-induced damages. From the results of this experiment and of the MV/light experiments (Figs. 5 and 6), we can conclude that reactive carbonyls mediated photooxidative damage of cells partially, but significantly.

\section{At-AER Protein Resides in Cytosol and Nucleus in Bright-Yellow 2 Cells}

The deduced amino acid sequence of At-AER does not have apparent organelle-targeting signal sequences, and hence is presumed to reside in cytosol (Babiychuk et al., 1995). We determined the intracellular protein localization by examining the in vivo behavior of the translational fusion protein between At-AER and the green fluorescent protein (GFP) from Aequorea victoria, which was expressed in tobacco Bright-Yellow 2 (BY-2) cells (Fig. 8). Strong green fluorescence was distributed in the periphery and the center of the cell (top section). An overlay of fluorescent and phase-contrast images (bottom section) revealed that the fluorescence was distributed in cytoplasm around vacuoles and along plasma membranes, and in the nucleoplasm of nuclei. Several dark spots in the nuclei indicated that the fusion protein was excluded from nucleoli. The fluorescence signal did not associate with vacuoles, proplastids, mitochondria, or peroxisomes. Thus, At-AER GFP is localized in cytosolic and nuclear compartments of tobacco cells. Specifically, the reactive carbonyls produced under photooxidative stress were scavenged in the cytosol and nucleus. Although unidentified yet, the primary production sites of the reactive carbonyls are presumably very close to the primary sites of ROS production. ROS are mainly produced in chloroplasts under the MV/ light conditions (Slooten et al., 1995) and in both chloroplasts and peroxisomes under intense light (Noctor et al., 2002). Then, the reactive carbonyls are able to diffuse from the primary production sites to cytosol, where At-AER would detoxify them. Such an indirect action could explain the relatively modest protective effect in spite of the high level expression of At-AER in the transgenic tobaccos.

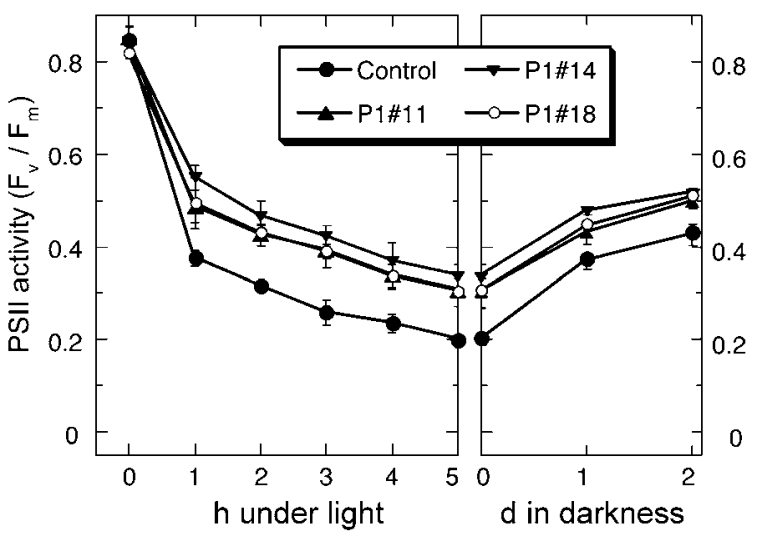

Figure 7. Phototolerance of the At-AER-overproducing tobaccos. Control and At-AER-overproducing tobacco plants were cultured on glass wool soaked with Hyponex nutrient solution at $25^{\circ} \mathrm{C}$ in a $16 / 8$-h at $50 \mu \mathrm{mol}$ photons $\mathrm{m}^{-2} \mathrm{~s}^{-1}$ photoperiod with white-fluorescent lamps. Fully expanded leaves on 9- to 11-week-old plants were illuminated with cold white light at 2,000 $\mu \mathrm{mol} \mathrm{m} \mathrm{m}^{-2} \mathrm{~s}^{-1}$ for the indicated period. After $5 \mathrm{~h}$ illumination, the plant was kept in darkness for $2 \mathrm{~d}$. For determination of $F_{\mathrm{v}} / F_{\mathrm{m}}$, the illumination was interrupted every $1 \mathrm{~h}$ with a 5 -min darkness. Data are presented as means (with error bars of SD) of three plants. Illumination at $10 \mu \mathrm{mol} \mathrm{m} \mathrm{m}^{-2} \mathrm{~s}^{-1}$ did not cause decreases in the $F_{\mathrm{v}} / F_{\mathrm{m}}$ value in any of the plants (data not shown). 


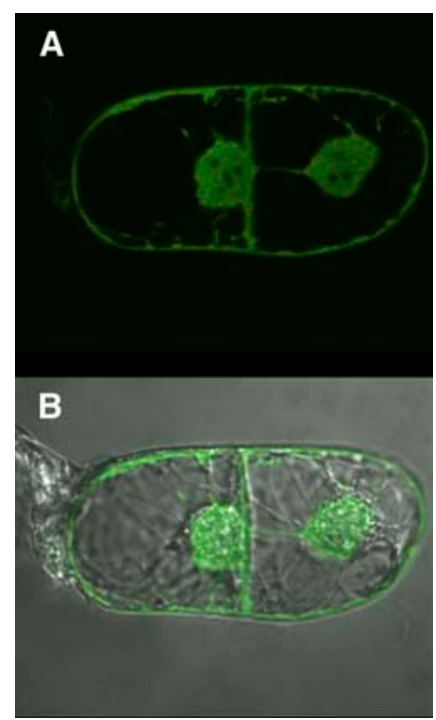

Figure 8. Intracellular localization of At-AER-GFP fusion in tobacco BY-2 cells. Images show single microscope sections of two dividing BY-2 cells acquired with a laser-scanning confocal microscope. Top image shows GFP fluorescence, and bottom image merges the fluorescence and the phase contrast images of the same cells.

\section{DISCUSSION}

Cytotoxicity of the lipid peroxide-derived aldehydes in plants and the importance of the cellular capacity to scavenge them have been suggested by the recent studies using transgenic plants that overexpress At-ALDH (Ramanjulu et al., 2003) or AKR (Hideg et al., 2003). In this study, we have elucidated the in vivo function of a new enzyme At-AER to protect cells from photooxidative stress, and thereby we provide three new pieces of knowledge about the metabolism of lipid peroxide-derived aldehydes. (1) Not only simple aldehydes such as malondialdehyde but the reactive carbonyls, i.e. aldehydes and ketones that have the $\alpha, \beta$-unsaturated bond, are produced in plants during MV-induced oxidative stress and participated in the cellular injury. (2) Reactive carbonyls are involved also in the intense light-induced photooxidative stress. (3) The scavenging of reactive carbonyls by the AER reaction thus is a new antioxidative defense.

Cellular damages caused by photooxidative stress have been ascribed to ROS, such as hydroxyl radicals, $\mathrm{H}_{2} \mathrm{O}_{2}$, singlet oxygen and superoxide, as well as highly oxidizing organic molecules like triplet state of chlorophylls. Our current results demonstrate that the scavenging of reactive carbonyls alleviated the cell injury caused by photooxidative stress, thus indicating the participation of reactive carbonyls in the intense lightinduced damages of cells. This further suggests that leaves in natural environments are potentially under the threat of reactive carbonyls as well as that of ROS.

The three plant enzymes that scavenge the lipid peroxide-derived aldehydes, i.e. AER, ALDH, and AKR, have distinct substrate specificities and hence appear to act complementarily in scavenging lipid peroxide- derived toxins in plants (Fig. 9). At-AER is highly specific to 2-alkenals including HNE and to oxenes (Table I), but unreactive with $n$-alkanals (Mano et al., 2002). Arabidopsis ALDH3 is highly reactive with $n$-alkanals but not with HNE (Kirch et al., 2001). Thus, 2-alkenals such as HNE and HHE are preferentially reduced by AER to form alkanals. Although less toxic than 2-alkenals, alkanals are still reactive because of the aldehyde moiety and will be oxidized with ALDH to inert carboxylates. Alternatively, aldehydes may be reduced to alcohols with AKR (Oberschall et al., 2000). Notably, AER exhibits a high level of activity in reducing oxenes to ketones. By this activity, AER will significantly contribute to cellular protection when oxenes such as 9-oxoODE and 13-oxoODE are generated.

In addition to the At-AER gene At5g16970, a dozen of genes homologous to it are identified in the Arabidopsis genome (Mano et al., 2002). Judging from the amino acid sequence homology or from the function to complement the deficiency of stress tolerance of yeast cells (Babiychuk et al., 1995), some of them are very likely to encode AER isoforms that participate in the detoxification of reactive carbonyls. Similarly, there are probably some more ALDH and AKR homologous genes that encode corresponding enzymes specific to the lipid peroxide-derived aldehydes. Investigation of the enzymic characters and intracellular and tissue localization of these isoforms, and the regulation of expression especially in response to various environmental stresses is required for the comprehensive understanding of the metabolism of lipid peroxidederived toxins.

Which species of the reactive carbonyls are produced during photooxidative stress and the mechanisms of their production are largely unknown. Occurrence of HNE in French beans (Phaseolus vulgaris) infected with Botrytis cinerea (Muckenschnabel et al., 2001) and that of HNE and HHE in barley (Hordeum vulgare) leaves treated with methyl jasmonate (Kohlmann et al., 1999) have been reported. Upon such biological stimuli,

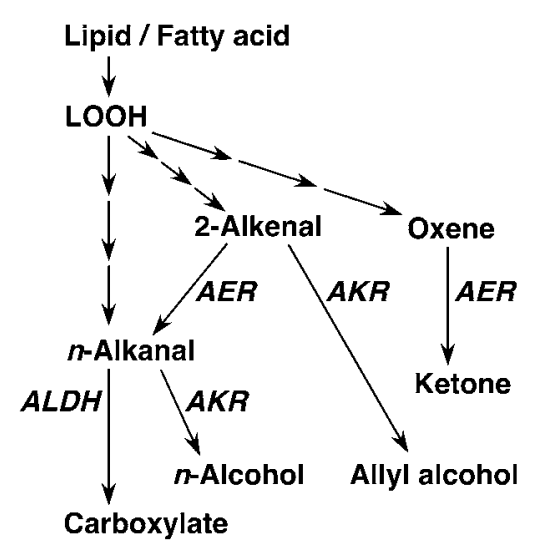

Figure 9. Pathways of detoxification of lipid peroxide-derived reactive carbonyls and saturated aldehydes in plants. Enzyme abbreviations are as follows: AER, Alkenal reductase; AKR, aldo-keto reductase; and $\mathrm{ALDH}$, aldehyde dehydrogenase. 
plants produce specific kinds of reactive carbonyls via certain metabolic pathways, i.e. the cleavage of free fatty acids from membrane lipids with the catalysis of lipases, the conversion of unsaturated fatty acids to lipid peroxides with lipoxygenases, and the conversion of lipid peroxides to various metabolites via seven major alternative pathways, some of which lead to the formation of reactive carbonyls (Schaller, 2001). On the other hand, under abiotic stress conditions such as those of photooxidative stress, highly reactive species, such as hydroxyl radical, $\mathrm{HO}_{2}$ (the protonated form of superoxide radical), or singlet oxygen, would oxidize both membrane lipids and free fatty acids to produce various species of lipid peroxides, from which various reactive carbonyls can be generated through nonenzymic reactions (Lee et al., 2001; Schneider et al., 2001). It is also possible that acrolein, the smallest and one of the most toxic 2-alkenals, is produced during the oxidation of lipids (Uchida et al., 1998). Chemical identification of the reactive aldehydes produced during photooxidative stress and elucidation of their production mechanism are currently carried out.

Although details have yet to be investigated, a possible scheme of the reactive carbonyls-induced injury of plant cells is proposed as follows: When reactive carbonyls are produced continuously, GSH, the primary defense molecule against reactive carbonyls in cells, is consumed, leading to an exacerbation of oxidative stress (Uchida, 2003; Park et al., 2005). As a result, the steady-state concentrations of reactive carbonyls are raised and many biomolecules comprising thiols, amino groups, or imidazoles are covalently modified. In vitro studies showed that HNE inactivates glyceraldehyde 3-P dehydrogenase from rabbit (Uchida and Stadtman, 1993), Glc 6-P dehydrogenase from Leuconostoc mesenteoides (Szweda et al., 1993), GST from mouse (Mitchell et al., 1995), and GSH reductase (Vander Jagt et al., 1997) and aldose reductase (Del Corso et al., 1998) from bovine. Acrolein also inactivates thioredoxin and thioredoxin reductase in human cells (Yang et al., 2004; Park et al., 2005). These enzymes in plants are potential targets of reactive carbonyls. Furthermore, chloroplasts have several thiol-regulated enzymes in the Calvin cycle, which can be also attacked by reactive carbonyls. Indeed, we have recently observed that carbon fixation activity in isolated chloroplasts is greatly reduced by HNE and other reactive carbonyls (J. Mano, unpublished data). Under photooxidative stress, reactive carbonyls would inactivate these enzymes in plant cells to result in an extensive disintegration of cellular function.

The Gly decarboxylase complex in pea (Pisum sativum) mitochondria, a key enzyme in the photorespiration pathway, is strongly inactivated by HNE (Taylor et al., 2002), and probably by other reactive carbonyls. The overexpressed At-AER could prevent the inhibition of this mitochondrial enzyme and contribute to phototolerance of the leaves, which would be severely damaged by intense light if photorespiration is suppressed.

\section{CONCLUSION}

Heterologous expression of At-AER in tobacco suppressed the damages of leaf tissue by the exogenously added reactive carbonyl HNE. The leaves of At-AERoverproducing tobaccos suffered less damage caused by photooxidative stress due to MV/light or to intense light only. Thus, a considerable part of photooxidative injury in leaves is accounted for by the toxicity of the lipid peroxide-derived reactive carbonyls. The capacity to scavenge reactive carbonyls is critical for the protection of plant cells.

\section{MATERIALS AND METHODS}

\section{Enzymes and Chemicals}

Recombinant At-AER with poly-His $(6 \times$ His $)$ tagged at the $\mathrm{N}$ terminus was overproduced in Escherichia coli and purified as reported previously (Mano et al., 2000). HNE was purchased from Alexis Japan care of Biolinks K.K. ONE was a generous gift of Dr. Koji Uchida (Nagoya University). 9-OxoODE and 13-oxoODE were from Cayman Chemical.

\section{GC/MS Analysis}

A GCMS-QP 5050 system (Shimadzu) with a DB-WAX column $(0.25 \mathrm{~mm} \times$ $60 \mathrm{~cm}$; J\&W Science) was used. The carrier gas was helium at $200 \mathrm{kPa}$. The samples were measured in the electron-impact mode, using the split-injection mode with an injector temperature of $240^{\circ} \mathrm{C}$. The column temperature was $40^{\circ} \mathrm{C}$ for the initial $5 \mathrm{~min}$, which was gradually raised to $200^{\circ} \mathrm{C}$ over the next $25 \mathrm{~min}$. The mass was scanned from mass-to-charge ratio 45 to 350 .

\section{Generation, Screening, and Culture of Transgenic Tobacco Lines}

Tobacco (Nicotiana tabacum) cv Petit Havana SR1 was grown in vitro on the Murashige and Skoog medium supplemented with $0.8 \%$ agar, 3\% Suc (w/v), and $2.5 \mathrm{~mm}$ MES-NaOH, pH 5.7, at $23^{\circ} \mathrm{C}$ in a 16-h-light/8-h-dark cycle (light intensity, $50 \mu \mathrm{mol} \mathrm{m} \mathrm{m}^{-2} \mathrm{~s}^{-1}$ ). To construct a binary vector p35SP1S, in which At-AER cDNA is under the control of the 355 promoter, the full-length cDNA of the gene At5g16970 was cloned as a blunt-ended NotI fragment into the bluntended $\mathrm{XbaI}$ site of the binary vector pGSVE9 (E. Babiychuk, unpublished data). The T-DNA in this vector also contains the hygromycin-B phosphotransferase CDS under the control of the nopaline synthase promoter, and this geneexpression cassette was used as a selectable genetic marker. The T-DNA was introduced into plant cells by cocultivation of tobacco leaf disks with Agrobacterium tumefaciens C51C1 Rifr (pGV2260; p35SP1S). Twenty-one independent hygromycin-resistant lines of transgenic tobacco obtained were first screened for transgene expression by RNA gel-blot hybridization of total RNA with At-AER (i.e. P1) cDNA as a probe. The specificity of DNA-RNA hybridization was assessed by comparing the hybridization results with RNA from plants transformed with T-DNA of pGSVE9 (i.e. empty vector control). The plants were further screened for the expression of transgene using RNA gel-blot analysis, and $\mathrm{F}_{2}$ progeny of the transgenic lines exhibiting high levels of the transcript were examined for the level of At-AER by western blotting using the antibody against recombinant At-AER (Mano et al., 2002). There was a direct correlation between the mRNA levels and the protein levels in transgenic tobacco lines P1\#11, P1\#14, and P1\#18 as compared with the control plants, which were transformed with the empty vector (data not shown). Progenies from homozygous individuals of these lines were chosen for further analysis.

Unless otherwise stated, these tobacco plants were cultured on soil supplemented with Hyponex in a growth chamber in a 16/8-h photoperiod at $100 \mu \mathrm{mol} \mathrm{m} \mathrm{m}^{-2}$ with white-fluorescent lamps, with day and night temperatures of $25^{\circ} \mathrm{C}$ and $15^{\circ} \mathrm{C}$, respectively.

\section{Enzyme Assays}

Leaf tissue was homogenized and extracted in $50 \mathrm{~mm}$ potassium phosphate, $\mathrm{pH} 7.0$, containing $10 \%(\mathrm{w} / \mathrm{v})$ polyvinylpolypyrrolidone. Homogenates 
were passed through a layer of Miracloth (Calbiochem), and cell debris was pelleted by centrifugation at $8,000 \mathrm{~g}$ for $10 \mathrm{~min}$. The supernatant was desalted by passing it through a Sephadex G25 column equilibrated with $50 \mathrm{~mm}$ potassium phosphate, $\mathrm{pH}$ 7.0. For measurements of APX activity, both the extraction and desalting media were supplemented with $5 \mathrm{~mm}$ ascorbate and $0.5 \mathrm{~mm}$ diethylenetriamine- $N, N, N^{\prime}, N^{\prime \prime}, N^{\prime \prime}$-pentaacetic acid. SOD, APX, and catalase were assayed as previously reported (Mano et al., 2001). AER activity was assayed by the oxidation rate of NADPH at $340 \mathrm{~nm}$ in a reaction mixture $(1 \mathrm{~mL})$ containing $50 \mathrm{~mm}$ MES-NaOH, pH 6.0, 0.1 mM NADPH, and $0.1 \mathrm{~mm}$ electron acceptor (Mano et al., 2002). Electron acceptors were dissolved in dimethylsufoxide. Inhibition of At-AER by the solvent $(1 \%[v / v])$ was corrected by separately estimating its inhibition on the diamide-reducing activity (Mano et al., 2000). Protein was determined using Coomassie Brilliant Blue protein assay solution (Nakalai Tesque) with bovine serum albumin as a standard.

\section{Treatment of Tobacco Leaves with MV or High Light and Evaluation of Damages}

All the procedures were carried out at $25^{\circ} \mathrm{C}$, unless otherwise stated. For MV treatment, leaf discs $\left(1.5 \mathrm{~cm}^{2}\right.$ each) were floated on $3 \mathrm{~mL}$ of MV solution in a petri dish, and incubated in darkness for $16 \mathrm{~h}$. The leaf discs were then illuminated with white-fluorescent lamps for $2 \mathrm{~h}$ and further incubated in darkness for $20 \mathrm{~h}$. For the intense-light treatment, a small area $(2 \mathrm{~cm}$ in diameter) of a fully expanded mature leaf on a plant was illuminated in ambient air with white light at 2,000 $\mu \mathrm{mol}$ photons $\mathrm{m}^{-2} \mathrm{~s}^{-1}$ from a Schott KL 1500 halogen lamp delivered through a fiber optics and a heat-cut filter. The $F_{\mathrm{v}} / F_{\mathrm{m}}$ value was determined using a MINI-PAM chlorophyll fluorometer (Walz) with a probe of 2-mm (for leaf disks) or 8-mm (for leaves) diameter. Leaf disks or leaves were incubated in darkness for $5 \mathrm{~min}$ prior to every measurement.

\section{Expression of AER-GFP Fusion in Tobacco BY-2 Cells}

The Aequorea victoria GFP version, whose coding region was optimized for expression in plant cells and derived from pBIN-m-gfp5-ER, was a generous gift of Jim Haseloff (University of Cambridge). The analyzed translational fusions carried GFP at the $C$ terminus of the fusion protein. Using the Arabidopsis (Arabidopsis thaliana) P1 cDNA-encoding At-AER (Babiychuk et al., 1995; corresponding to the MIPS gene code At5g16970) as a template, the complete coding region without the stop codon was amplified by PCR with the forward and reverse primers of the following sequence: $5^{\prime}$-AA CTC GAG ACT AGT ATG ACG GCG ACG AAC-3' and 5' -AA ACT AGT TTA GAT CTT CTC ACG AGC AAC-3'. The PCR product was subcloned into the SmaI site of the pUC18 (Amersham Bioscience), and the At-AER coding region was then cloned as an XhoI/BglII fragment in the binary vector pSL10 (E. Babiychuk, unpublished data) to form pP1-GFP. The tobacco BY-2 cells were transformed by cocultivation with the A. tumefaciens strain EHA 101[pP1-GFP], according to Shaul et al. (1996), with modifications. Briefly, $6 \mathrm{~mL}$ of a 4-d-old BY-2 cell culture were combined with $100 \mu \mathrm{L}$ of an overnight-grown Agrobacterium strain, and cells were cocultured in a $10-\mathrm{cm}$ petri dish for $4 \mathrm{~d}$ at room temperature. Stably transformed tobacco cells were selected and propagated on agar-solidified BY-2 medium supplemented with $10 \mathrm{mg} \mathrm{L}^{-1}$ hygromycin B, $0.5 \mathrm{~g} \mathrm{~L}^{-1}$ vancomycin, and $0.5 \mathrm{~g} \mathrm{~L}^{-1}$ cefatoxime. At-AER-GFP fusion protein in the transformed cells was detected by fluorescence (excitation at $488 \mathrm{~nm}$, emission filter 505-530 nm) on an LSM510 laser scanning confocal microscope (Carl Zeiss).

Sequence data from this article can be found in the GenBank/EMBL data libraries under accession numbers AY120718, AY058070, and BT022058.

\section{ACKNOWLEDGMENTS}

The authors would like to thank Christophe Gilot and the sequencing group in Ghent for synthesizing the oligonucleotides and sequencing the constructs, Gilbert Engler (Ghent) for assistance with the confocal microscope, and Stijn Debruyne (Ghent) and Hirokazu Hosoi (Yamaguchi) for their technical assistance. We also wish to express our gratitude to Professors Pablo Vera and Vicente Conejero (Instituto de Biologia Molecular y Cellular de Plantas, Valencia, Spain) for their facilities, in which the transgenic tobacco plants were generated.
Received August 24, 2005; revised September 28, 2005; accepted October 4, 2005; published November 18, 2005

\section{LITERATURE CITED}

Asada K (1999) The water-water cycle in chloroplasts: scavenging of active oxygens and dissipation of excess photons. Annu Rev Plant Physiol Plant Mol Biol 50: 601-639

Asada K, Endo T, Mano J, Miyake C (1998) Molecular mechanism for relaxation of and protection from light stress. In $\mathrm{K}$ Satoh, N Murata, eds, Stress Response of Photosynthetic Organisms. Elsevier, Amsterdam, pp 37-52

Babiychuk E, Kushnir S, Belles-Boix E, Van Montagu M, Inzé D (1995) Arabidopsis thaliana NADPH oxidoreductase homologs confer tolerance of yeasts toward the thiol-oxidizing drug diamide. J Biol Chem 270: 26224-26231

Del Corso A, Dal Monte M, Vilardo PG, Cecconi I, Moschini R, Banditelli S, Cappiello M, Tsai L, Mura U (1998) Site specific inactivation of aldose reductase by 4-hydroxynonenal. Arch Biochem Biophys 350: 245-248

Demmig-Adams B (1990) Carotenoids and photoprotection in plants: a role for the xanthophyll zeaxanthin. Biochim Biophys Acta 1020: 1-24

Desikan R, A-H-Mackerness S, Hancock JT, Neill SJ (2001) Regulation of the Arabidopsis transcriptome by oxidative stress. Plant Physiol 127: 159-172

Dick RA, Kwak M-K, Sutter TR, Kensler TW (2001) Antioxidative function and substrate specificity of NAD(P)H-dependent alkenal/one oxidoreductase. J Biol Chem 276: 40803-40810

Dittberner U, Eisenbrand G, Znakl H (1995) Genotoxic effects of the $\alpha, \beta$-unsaturated aldehydes 2-trans-butenal, 2-trans-hexenal and 2-trans, 6-cis-nonadienal. Mutat Res 335: 259-265

Esterbauer H, Schaur RJ, Zollner H (1991) Chemistry and biochemistry of 4-hydroxynonenal, malonaldehyde and related aldehydes. Free Radic Biol Med 11: 81-128

Fleming HP, Cobb WY, Etchells JL, Bell TA (1968) The formation of carbonyl compounds in cucumber. J Food Sci 33: 572-576

Hartley DP, Ruth JA, Petersen DR (1995) The hepatocellular metabolism of 4-hydroxynonenal by alcohol dehydrogenase, aldehyde dehydrogenase, and glutathione $S$-transferase. Arch Biochem Biophys 316: 197-205

Hideg É, Nagy T, Oberschall A, Dudits D, Vass I (2003) Detoxification function of aldose/aldehyde reductase during drought and ultraviolet-B (280-320 nm) stresses. Plant Cell Environ 26: 513-522

Kirch H-H, Nair A, Bartels D (2001) Novel ABA- and dehydrationinducible aldehyde dehydrogenase genes isolated from the resurrection plant Craterostigma plantagineum and Arabidopsis thaliana. Plant J 28: 555-567

Kohlmann M, Bachmann A, Weichert H, Kolbe A, Balkenhohl T, Wasternack C, Feussner I (1999) Formation of lipoxygenase-pathwayderived aldehydes in barley leaves upon methyl jasmonate treatment. Eur J Biochem 260: 885-895

Kozaki A, Takeba G (1996) Photorespiration protects C3 plants from photooxidation. Nature 384: 556-560

Külheim C, Ågren J, Jansson S (2002) Rapid regulation of light harvesting and plant fitness in the field. Science 297: 91-93

Kushnir S, Babiychuk E, Kampfenkel K, Belles-Boix E, Van Montagu M, Inzé D (1995) Characterization of Arabidopsis thaliana cDNAs that render yeasts tolerant toward the thiol-oxidizing drug diamide. Proc Natl Acad Sci USA 92: 10580-10584

Lee SH, Blair IA (2000) Characterization of 4-oxo-2-nonenal as a novel product of lipid peroxidation. Chem Res Toxicol 13: 698-702

Lee SH, Oe T, Blair IA (2001) Vitamin C-induced decomposition of lipid peroxides to endogenous genotoxins. Science 292: 2083-2086

Mano J, Babiychuk E, Belles-Boix E, Hiratake J, Kimura A, Inzé D, Kushnir S, Asada K (2000) A novel NADPH:diamide oxidoreductase activity in

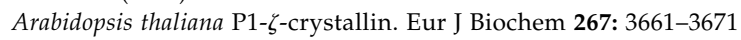

Mano J, Ohno C, Domae Y, Asada K (2001) Chloroplastic ascorbate peroxidase is the primary target of methylviologen-induced photooxidative stress in spinach leaves: its relevance to monodehydroascorbate radical detected with in vivo ESR. Biochim Biophys Acta 1504: 276-288

Mano J, Torii Y, Hayashi S, Takimoto K, Matsui K, Nakamura K, Inzé D, Babiychuk E, Kushnir S, Asada K (2002) The NADPH:quinone oxidoreductase P1- $\zeta$-crystallin in Arabidopsis catalyzes the $\alpha, \beta$-hydrogenation 
of 2-alkenals: detoxification of the lipid peroxide-derived reactive aldehydes. Plant Cell Physiol 23: 1445-1455

Mitchell AE, Morin D, Lamé MW, Jones AD (1995) Purification, mass spectrometric characterization, and covalent modification of murine glutathione $S$-transferase. Chem Res Toxicol 8: 1054-1062

Muckenschnabel I, Williamson B, Goodman BA, Lyon GD, Stewart D, Deighton N (2001) Markers for oxidative stress associated with soft rots in French beans (Phaseolus vulgaris) infected by Botrytis cinerea. Planta 212: $376-381$

Munekage Y, Hashimoto M, Miyake C, Tomizawa KI, Endo T, Tasaka M, Shikanai T (2004) Cyclic electron flow around photosystem I is essential for photosynthesis. Nature 429: 579-582

Noctor G, Veljovic-Jovanovic S, Driscoll S, Novitskaya L, Foyer CH (2002) Drought and oxidative load in the leaves of $\mathrm{C} 3$ plants: a predominant role of photorespiration? Ann Bot (Lond) 89: 841-850

Nordling E, Jörnvall H, Persson B (2002) Medium-chain dehydrogenases/ reductases (MDR). Eur J Biochem 269: 4267-4276

Oberschall A, Deák M, Török K, Sass L, Vass I, Kovács I, Fehér A, Dudits D, Horváth G (2000) A novel aldose/aldehyde reductase protects transgenic plants against lipid peroxidation under chemical and drought stress. Plant J 24: 437-446

Pappa A, Chen C, Koutalos Y, Townsend AJ, Vasilou V (2003) ALDH3A1 protects human corneal epithelial cells from ultraviolet- and 4-hydroxy2-nonenal-induced oxidative damage. Free Radic Biol Med 34: $1178-1189$

Park YS, Misonou Y, Fujiwara N, Takahashi M, Miyamoto Y, Koh YH, Suzuki K, Taniguchi N (2005) Induction of thioredoxin reductase as an adaptive response to acrolein in human umbilical vein endothelial cells. Biochem Biophys Res Commun 327: 1058-1065

Ramanjulu S, Bartels D, Kirch H-H (2003) Overexpression of a stressinducible aldehyde dehydrogenase gene from Arabidopsis thaliana in transgenic plants improves stress tolerance. Plant J 35: 452-464

Schaller F (2001) Enzymes of the biosynthesis of octadecanoid-derived signalling molecules. J Exp Bot 52: 11-23

Schieberle P, Ofner S, Grosch W (1990) Evaluation of potent odorants in cucumbers (Cucumis sativus) and Muskmelons (Cucumis melo) by aroma extract dilution analysis. J Food Sci 55: 193-195

Schneider C, Tallman KA, Porter NA, Brash AR (2001) Two distinct pathways of formation of 4-hydroxynonenal. J Biol Chem 276: 2083120838

Shaul O, Mironov V, Burssens S, Van Montagu M, Inzé D (1996) Two Arabidopsis cyclin promoters mediate distinctive transcriptional oscillation in synchronised tobacco BY-2 cells. Proc Natl Acad Sci USA 93: $4868-4872$
Slooten L, Capiau K, Van Camp W, Van Montagu M, Sybesma C, Inzé D (1995) Factors affecting the enhancement of oxidative stress tolerance in transgenic tobacco overexpressing manganese superoxide dismutase in the chloroplasts. Plant Physiol 107: 737-750

Srivastava S, Chandra A, Wang L-F, Seifer WE Jr, DaGue BB, Ansari NH, Srivastava SK, Bhatnager A (1998) Metabolism of the lipid peroxidation product, 4-hydroxy-trans-2-nonenal, in isolated perfused rat heart. J Biol Chem 273: 10893-10900

Srivastava S, Dixit BL, Cai J, Sharma S, Hurst HE, Bhatnager A, Srivastava SK (2000) Metabolism of lipid peroxidation product, 4-hydroxynonenal (HNE) in rat erythorocytes: role of aldose reductase. Free Radic Biol Med 29: 642-651

Szweda LI, Uchida K, Tsai L, Stadtman ER (1993) Inactivation of glucose6-phosphate dehydrogenase by 4-hydroxy-2-nonenal. J Biol Chem 268: 3342-3347

Taylor NL, Day DA, Millar AH (2002) Environmental stress causes oxidative damage to plant mitochondria leading to inhibition of glycine decarboxylase. J Biol Chem 277: 42662-42668

Uchida K (2003) 4-Hydroxy-2-nonenal: a product and mediator of oxidative stress. Prog Lipid Res 42: 318-343

Uchida K, Kanematsu M, Morimitsu Y, Osawa T, Noguchi N, Niki E (1998) Acrolein is a product of lipid peroxidation reaction. J Biol Chem 273: 16058-16066

Uchida K, Stadtman ER (1993) Covalent attachment of 4-hydroxynonenal to glyceraldehyde-3-phosphate dehydrogenase. J Biol Chem 268: 6388-6393

van Kooten O, Snel JFH (1990) The use of chlorophyll fluorescence nomenclature in plant stress physiology. Photosynth Res 25: 147-150

Vander Jagt D, Hunsaker LA, Vander Jagt TJ, Gomez MS, Gonzales DM, Deck LM, Royer RE (1997) Inactivation of glutathione reductase by 4-hydroxynonenal and other endoneous aldehydes. Biochem Pharmacol 53: $1133-1140$

Vollenweider S, Weber H, Stolz S, Chételet A, Farmer EE (2000) Fatty acid ketodienes and fatty acid ketotrienes: Michael addition acceptors that accumulate in wounded and diseased Arabidopsis leaves. Plant J 24: 467-476

Vranová E, Atiharpongkul S, Villarrolel R, Van Montagu M, Inzé D, Van Camp W (2002) Comprehensive analysis of gene expression in Nicotiana tabacum leaves acclimated to oxidative stress. Proc Natl Acad Sci USA 99: $10870-10875$

Yang X, Wu X, Choi YE, Kern JC, Kehler JP (2004) Effect of acrolein and glutathione depleting agents on thioredoxin. Toxicology 204: 209-218 